\title{
Pathogen-derived biomarkers for active tuberculosis diagnosis
}

\author{
Paula Tucci $^{1}{ }^{*}$, Gualberto González-Sapienza ${ }^{2}$ and Monica Marin ${ }^{1}$ \\ ' Sección Bioquímica, Facultad de Ciencias, Universidad de la República, Montevideo, Uruguay \\ ${ }^{2}$ Cátedra de Inmunología, DEPBIO, Instituto de Higiene, Facultad de Química, Universidad de la República, Montevideo, Uruguay
}

\section{Edited by:}

Evangelos Giamarellos-Bourboulis, University of Athens, Greece

\section{Reviewed by:}

George Dimopoulos, University Hospital Attikon, Greece

Mandy Sin, Stanford University, USA

\section{*Correspondence:}

Paula Tucci, Sección Bioquímica,

Facultad de Ciencias, Universidad de

la República, Iguá 4225,

11400, Montevideo, Uruguay

e-mail: ptucci@fcien.edu.uy
Tuberculosis (TB) is an infectious disease caused by members of Mycobacterium tuberculosis complex. Despite the availability of effective treatments, TB remains a major public health concern in most low and middle-income countries, representing worldwide the second leading cause of death from an infectious disease. Inadequate case detection and failures to classify the disease status hamper proper TB control. The limitations of the conventional diagnostic methods have encouraged much research activities in this field, but there is still an urgent need for an accurate point of care test for active TB diagnosis. A rapid, precise, and inexpensive TB diagnostic test would allow an earlier implementation of an appropriate treatment and the reduction of disease transmission. Pathogen-derived molecules present in clinical specimens of affected patients are being validated for that purpose. This short review aims to summarize the available data regarding biomarkers derived from $M$. tuberculosis, and their current usage in active TB diagnosis.

Keywords: M. tuberculosis, active infection, diagnosis, point of care, biomarkers

\section{INTRODUCTION}

Tuberculosis (TB) is a major global health problem and one of the most important causes of death from an infectious disease. In 2012, 8.6 million people developed TB and 1.3 million died from the disease (WHO, 2013). Despite substantial investments and progress made in the implementation of Stop TB strategy by the World Health Organization (WHO), inadequate case detection and failures to accurately classify the disease status still hamper the control of TB (Wallis et al., 2010a; McNerney et al., 2012). Most humans infected with Mycobacterium tuberculosis (MTB) remain asymptomatic, and only a small proportion develops active TB disease. Typically the bacterium establishes a latent infection and the lifetime risk of developing the disease is near 10\% unless an individual becomes immunocompromised, at which time the risk increases significantly (Young et al., 2008). TB is usually a chronic, slowly progressing disease that often keeps undiagnosed in patients for many years. In adults the most common form is chronic pulmonary $\mathrm{TB}$, while extrapulmonary $\mathrm{TB}$ is especially common in children and HIV-coinfected patients (Jain, 2011).

The diagnosis of active TB is critical for controlling the disease. Conventional diagnostic methods of active TB include sputum smear microscopy (pulmonary TB) and M. tuberculosis isolation in bacteriological culture (currently the gold standard for definitive diagnosis of pulmonary and extrapulmonary TB). Although these methods are widely used for diagnosing TB, they suffer of specificity and sensitivity limitations (Tiwari et al., 2007; WHO, 2013), and microbiological culture takes several weeks to confirm a clinical diagnosis. Besides, both methods require highly skilled personnel and specialized laboratory infrastructure.

Recently, PCR based diagnostic methods were launched. The GeneXpert MTB/RIF (Cepheid Inc., USA) is a cartridge-based, automatic nucleic acid amplification test, for TB case detection and rifampicin resistance testing. It purifies, amplifies, and identifies targeted nucleic acid sequences in the TB genome, and provides results from unprocessed sputum samples in less than $2 \mathrm{~h}$ (Boehme et al., 2010). This assay showed a high sensitivity in both pulmonary (Boehme et al., 2010) and extrapulmonary TB (Hillemann et al., 2011). It was endorsed by WHO (2011a) for use in TB endemic countries. However, its high cost is a main barrier for the popularization of this new technology out of reference laboratories, in areas where the prevalence of the disease is higher (Steingart et al., 2012).

Unlike many other infectious diseases, in TB the specific antibody response is not so well understood. That is a consequence of the complex and highly evolved relationship of the pathogen with the immune system, its intracellular localization, and our partial understanding of its biology and host-pathogen interaction. This fact has largely frustrated the attempts to exploit the host response in antibody detection diagnostic assays, which could constitute an economical diagnostic alternative in low income countries (Young et al., 2008). A systematic review of the performance of various commercial serological tests has evidenced that this approach does not allow a reliable diagnosis of TB, reporting inconsistent, imprecise, and highly variable values for sensitivity and specificity (Steingart et al., 2011). Considering that situation in 2011, WHO issued a policy recommending not using these tests for the diagnosis of pulmonary and extra-pulmonary TB (WHO, 2011b).

In this context, a major focus of the WHO's global plan to stop TB is the development of a simple and cost-effective diagnostic method to improve case detection (Pollock et al., 2013). Until the moment TB lacks an accurate rapid point-of-care (POC) diagnostic test that could distinguish individuals with active TB from those with latent disease or not infected (McNerney et al., 
2012; Pollock et al., 2013). The failure of diagnostic tests based on the antibody response has greatly stimulated the interest in the development of rapid antigen detection methods (WHO, 2009). For that purpose much work is being performed aiming to discover and validate robust host and pathogen biomarkers of M. tuberculosis infection and disease (Doherty et al., 2009). This minireview covers M. tuberculosis-derived molecules identified in clinical samples of infected patients, and thus, could be proposed as diagnostic markers candidates. Bearing a potential correlation with the actual load of bacteria, they can be used both for diagnosis and treatment monitoring (WHO, 2009). Among these molecules, this review focuses on antigenic compounds that can be detected with antibodies in antigen detection assays, being particularly attractive for the development of POC diagnostic test. Other pathogen-derived markers [DNA, RNA, and molecules with enzymatic activities (Xie et al., 2012)] are out of the scope of this review.

\section{PATHOGEN-DERIVED BIOMARKERS}

A biomarker is defined as a parameter that can be objectively measured as an indicator of normal or pathogenic biological processes, or as an indicator of pharmacological responses to therapeutic interventions (Wallis et al., 2010a,b; McNerney et al., 2012). In routine clinical care, biomarkers allow stratification of individual patients, thus helping to develop targeted interventions that might not otherwise produce overall benefits (Wallis et al., 2010a).

In an infectious disease biomarkers can be either host or pathogen-derived (McNerney et al., 2012). Human immunodeficiency virus (HIV) infection offers a prime example of biomarker's utility both for initial diagnosis and for the evaluation of disease state and progression. After HIV infection, viral RNA, and p24 antigen detection are used to establish an early diagnosis. Afterward, to evaluate HIV progression, viral load is measured by viral RNA quantification, and disease evolution is evaluated through CD4+ cell counts (Constantine and Zink, 2005). In that case understanding of the pathogen dynamics and kinetics of the host immune response during the disease allowed the development of accurate diagnostic tests.

A main challenge in TB is to identify and validate consistent markers which could be translated into a specific and sensitive diagnostic test. Unfortunately, knowledge in that field is still partial, and requires a better understanding of the disease and the host-pathogen interaction (Young et al., 2008). It is expected that the identification of specific molecular markers would help to the development of an in vitro diagnostic test for M. tuberculosis active infection, which should be rapid, inexpensive, sensitive, and appropriate to be used in peripheral laboratories with low level of infrastructure.

\section{PRINCIPAL M. tuberculosis DERIVED BIOMARKERS}

To be considered as targets for antigen detection assays, pathogenderived molecules must reach the sample matrixes (sputum, urine, plasma, etc.) in detectable levels (Bekmurzayeva et al., 2013). To be valuable as diagnostic biomarkers these antigens should be specifically and ubiquitously detected in clinical samples of infected patients.
An antigen detection assay for TB could be performed using a variety of clinical specimens such us sputum, blood, urine, saliva, cerebrospinal fluid (CSF), and pleural fluid. Antigens that are shed from $M$. tuberculosis in infected tissues can be present in the body fluids surrounding these tissues wherefrom they can reach the blood circulation and be eliminated in urine, a highly practical specimen for diagnostic tests. Urine is safer to handle and less variable than sputum, besides it is easier to collect from both adults and children. Additionally, urine based assays could facilitate TB diagnosis in HIV co-infected patients, who normally have a low bacterial load in sputum (WHO, 2009). Finally, in patients suspected of extrapulmonary TB, an antigen detection test might prevent the use of more invasive tests (WHO, 2009; Flores et al., 2011). These characteristics, if paired with an appropriate and simple method for antigen detection, make this approach applicable at the community level of the health system, so major efforts are being made to identify pathogen-derived antigens excreted in urine (Choudhry and Saxena, 2002).

One of the most promising antigens that are being evaluated is lipoarabinomannan (LAM). LAM is a structurally important component of the outer cell wall of all bacteria of the genus Mycobacterium that is shed from metabolically active or degrading cells, is cleared by the kidney and detectable in urine (Hunter et al., 1986; Chan et al., 1991). Antigen detection assays were described for LAM, most of which are based on a sandwich capture ELISA format to detect LAM in sputum (Pereira Arias-Bouda et al., 2000) or urine (Hamasur et al., 2001; Boehme et al., 2005; Mutetwa et al., 2009). As it will be described below, this antigen is being currently evaluated by a lateral flow test for rapid LAM detection in urine (Minion et al., 2011).

In addition to LAM, defined M. tuberculosis protein antigens were assayed as target for antigen detection assays. The tested proteins are generally major components that have been identified by electrophoresis and mass spectrometry both in total extracts and culture filtrate of M. tuberculosis (Malen et al., 2007; Mattow et al., 2003). Table 1 summarizes available information from these antigens provided in TB Genomes Database (Reddy et al., 2009) and TubercuList (Lew et al., 2011). It is important to mention that many former published studies described the use of an antigen based only upon its apparent molecular weight on SDS-PAGE and without further identification of the protein. This is the case of a $55 \mathrm{kDa}$ antigen ( $\mathrm{Rv}$ not reported) present in serum of pulmonary (Attallah et al., 2003) and extra-pulmonary TB patients (Attallah et al., 2005), and a $20 \mathrm{kDa}$ antigen ( $\mathrm{Rv}$ not reported) detected in MTB crude extracts and serum of pulmonary TB patients (ElMasry et al., 2008).

More recently, high throughput approaches were designed to facilitate new biomarker discovery, based on proteomic approaches employing clinical samples from active TB patients. Thereby, four M. tuberculosis proteins were detected in urine samples, which were identified as a possible molybdopterin biosynthesis protein MoeX (Rv1681), a probable ornithine carbamoyltransferase ArgF (Rv1656), a probable homoserine O-acetyltransferase MetA $(\mathrm{Rv} 3341)$ and a probable $3^{\prime}$ phosphoadenosine $5^{\prime}$-phosphosulfate reductase CysH (Rv2392; Kashino etal., 2008; Napolitano etal., 2008). These proteins 


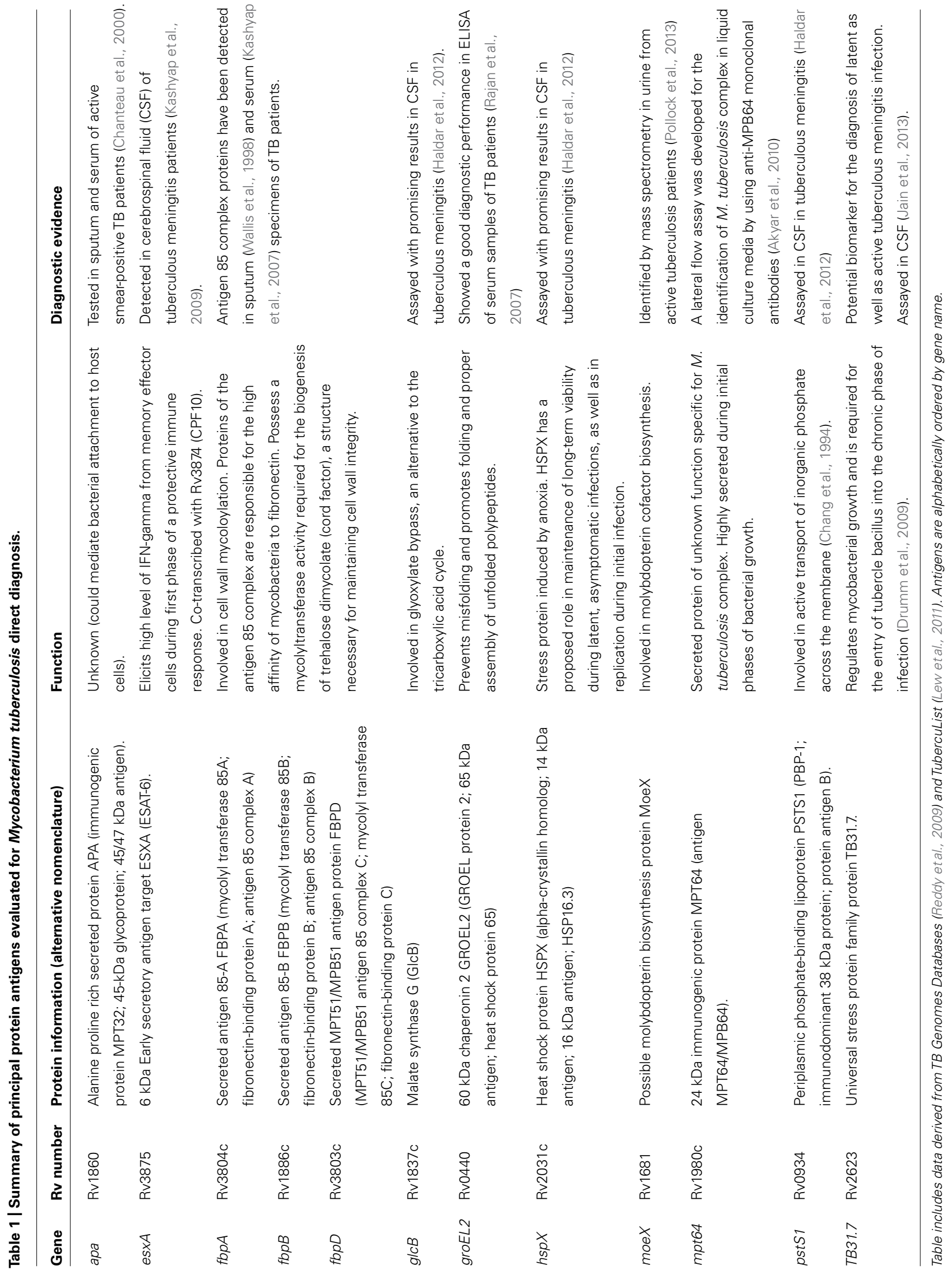


constitute interesting candidates for the development of antigen detection assays, and recently the gene coding for MoeX, unique to the $M$. tuberculosis complex, was clinically validated as a diagnostic biomarker for active pulmonary TB (Pollock et al., 2013).

\section{DIAGNOSTIC PERFORMANCE AND COMMERCIAL DEVELOPMENT}

A small number of commercial prototype TB diagnostic tests based on antigen detection have been developed, and some of them were evaluated for clinical diagnostic performance. These tests includes: Patho-TB (Anda Biologicals, France), Diagnos TB Ag (Biomed Industries, India), LAM-ELISA (Chemogen, USA, a prototype test not currently available), Clearview TB ELISA (Inverness Medical Innovations, USA) and Determine TB-LAM (Alere Inc., USA; Flores et al., 2011; Minion et al., 2011). Two recent systematic reviews and meta-analysis highlighted that these tests showed heterogeneous values of sensitivity and specificity through clinical evaluations (Flores et al., 2011; Minion et al., 2011).

Some of these tests were designed to detect different $M$. tuberculosis antigens in sputum. Patho-TB rapid diagnostic test uses polyclonal antibodies to detect mycobacterial antigens (including 65 and $85 \mathrm{kDa}$ antigens) in sputum samples, previously decontaminated and imprinted in a filter cartridge. This test showed a sensitivity ranging from 90 to $96 \%$ and specificity between 70 and $100 \%$ in different evaluation studies (Fabre et al., 2007; Alavi-Naini et al., 2009; Ben-Selma et al., 2009). Another rapid test designed to detect mycobacterial antigens in sputum [including LAM and antigen 85B (Rv1886)] using polyclonal antibodies is Diagnos TB Ag. The test comprises the inactivation and lysis of the sputum sample, loading of the sample on a membrane device and immune-detection of specific antigens. It showed a variable performance in two published studies: a sensitivity of $98 \%$ and specificity of $99 \%$ in TB infected HIV sero-positive patients (Chakraborty et al., 2009) versus a 60\% sensibility and 33\% specificity in HIV positive and TB negative infected patients (Reither et al., 2010).

Another group of tests is based on LAM detection in urine. Diagnostic tests based on the detection of LAM in urine were among the first to move from research to commercial stage, due to their promising initial results (Hamasur etal., 2001; Boehme etal., 2005). However, they have not yet been routinely applied in remote points of care settings (Minion et al., 2011; Pai and Pai, 2012). The conflicting results obtained with these tests can be explained, in part, by the lack of specificity of the anti-LAM antibodies, since even anti-LAM monoclonal antibodies cross-react with most species of Mycobacterium, including M. avium and M. leprae (Hunter et al., 1986; WHO, 2009).

The LAM-ELISA (Chemogen Inc., Portland, USA) was the first LAM targeting assayed prototype (Boehme et al., 2005; Daley et al., 2009; Lawn et al., 2009; Mutetwa et al., 2009; Reither et al., 2009). Afterward another commercial version named Clearview TB ELISA (Alere Inc., USA - formerly Inverness Medical Innovations, Inc.) was launched (Dheda et al., 2010; Shah et al., 2010). Both tests use polyclonal anti-LAM antibodies in a capture sandwich ELISA format. A meta-analysis of published clinical studies with different versions of these tests showed that $57 \%$ of urine samples from smear positive TB patients were positive for LAM, indicating that this test would not be sufficiently sensitive to replace sputum microscopy. Nevertheless, $41 \%$ of smear negative TB patients were positive for LAM, suggesting that LAM testing and sputum microscopy used together could help diagnose different groups of patients with TB (Minion et al., 2011). In addition, it has been reported that a pre-analytical 100-fold-concentrating step of urine samples increased significantly the sensitivity of the Clearview TB ELISA (Savolainen et al., 2013), yet the method still needs to be refined to become a viable tool for TB diagnosis.

Promisingly, a POC lateral flow dipstick version of urinary LAM detection (Determine TB LAM Ag, Alere Inc.) has been developed. Following its commercial launch in 2013, Determine TB-LAM remains the focus of ongoing clinical evaluation studies. This is a simple, low-cost, POC assay which provides a qualitative (yes/no) readout of TB diagnosis within $30 \mathrm{~min}$ (Lawn, 2014). While diagnostic evaluation of this kit showed a poor performance with unselected TB patients, combination of LAM lateral flow test with sputum microscopy demonstrated a diagnostic value in HIV immunocompromised TB patients (CD4 lymphocyte cell counts < 50/ $\mu$ L; Lawn et al., 2012; Peter et al., 2012). These and other studies largely confirm that the sensitivity of Determine TBLAM is greatest (range 60-70\%) among HIV-infected patients with the most advanced immunodeficiency (Lawn et al., 2013). HIV-associated pulmonary TB is of major concern in many countries of Africa, thus this kit could assist to establish a quicker diagnosis and an earlier treatment in this high risk population. As the evidence base grows, data on this assay would be reviewed by an expert panel convened by WHO to define the role of the assay as an add-on test within existing diagnostic algorithms (Lawn et al., 2013).

\section{CONCLUSION}

A reliable POC diagnostic test for active TB detection is urgently needed and much work is being done for that purpose. In the TB diagnostic field, antigen detection technologies and biomarker discovery strategies are rapidly evolving. While there are promising evidences endorsing some of the commercially available diagnostic tests, none of the new tools designed so far have shown an outstanding diagnostic performance as to promote its widespread application in medical practice. It is highly expected that in the coming years more light is shed to aid in that goal.

\section{ACKNOWLEDGMENTS}

We thank Dr. Carlos Rivas Chetto (CHLA-EP) for technical advice and fruitful discussions. This work was supported by Agencia Nacional de Investigación e Innovación (ANII, Uruguay) through Fondo María Viñas (FMV_3_2013_1_100859) and Universidad de la República, Uruguay.

\section{REFERENCES}

Akyar, I., Kocagoz, T., Sinik, G., Oktem, S., Aytekin, N., and Kocagoz, S. (2010). Lateral flow assay for rapid differentiation of Mycobacterium tuberculosis complex and 97 species of mycobacteria other than tuberculosis grown in LowensteinJensen and TK-SLC medium. Indian J. Med. Microbiol. 28, 308-312. doi: 10.4103/0255-0857.71817

Alavi-Naini, R., Metanat, M., Alijani, E., and Mozaffar, H. (2009). Patho-TB test for the rapid diagnosis of pulmonary tuberculosis. J. Res. Med. Sci. 14, 301-307. 
Attallah, A. M., Abdel Malak, C. A., Ismail, H., El-Saggan, A. H., Omran, M. M., and Tabll, A. A. (2003). Rapid and simple detection of a Mycobacterium tuberculosis circulating antigen in serum using dot-ELISA for field diagnosis of pulmonary tuberculosis. J. Immunoassay Immunochem. 24, 73-87. doi: 10.1081/IAS-120018470

Attallah, A. M., Osman, S., Saad, A., Omran, M., Ismail, H., Ibrahim, G., et al. (2005). Application of a circulating antigen detection immunoassay for laboratory diagnosis of extra-pulmonary and pulmonary tuberculosis. Clin. Chim. Acta 356 , 58-66. doi: 10.1016/j.cccn.2004.11.036

Bekmurzayeva, A., Sypabekova, M., and Kanayeva, D. (2013). Tuberculosis diagnosis using immunodominant, secreted antigens of Mycobacterium tuberculosis. Tuberculosis (Edinb.) 93, 381-388. doi: 10.1016/j.tube.2013.03.003

Ben-Selma, W., Ben-Kahla, I., Marzouk, M., Ferjeni, A., Ghezal, S., Ben-Said, M., et al. (2009). Rapid detection of Mycobacterium tuberculosis in sputum by PathoTB kit in comparison with direct microscopy and culture. Diagn. Microbiol. Infect. Dis. 65, 232-235. doi: 10.1016/j.diagmicrobio.2009.07.021

Boehme, C., Molokova, E., Minja, F., Geis, S., Loscher, T., Maboko, L., et al. (2005). Detection of mycobacterial lipoarabinomannan with an antigen-capture ELISA in unprocessed urine of Tanzanian patients with suspected tuberculosis. Trans R. Soc. Trop. Med. Hyg. 99, 893-900. doi: 10.1016/j.trstmh.2005.04.014

Boehme, C. C., Nabeta, P., Hillemann, D., Nicol, M. P., Shenai, S., Krapp, F., et al. (2010). Rapid molecular detection of tuberculosis and rifampin resistance. $N$. Engl. J. Med. 363, 1005-1015. doi: 10.1056/NEJMoa0907847

Chakraborty, N., Bhattacharyya, S., De, C., Mukherjee, A., Sarkar, R. N., Banerjee, D., et al. (2009). A rapid immunochromatographic assay for the detection of Mycobacterium tuberculosis antigens in pulmonary samples from HIV seropositive patients and its comparison with conventional methods. J. Microbiol. Methods 76, 12-17. doi: 10.1016/j.mimet.2008.09.005

Chan, J., Fan, X. D., Hunter, S. W., Brennan, P. J., and Bloom, B. R. (1991). Lipoarabinomannan, a possible virulence factor involved in persistence of Mycobacterium tuberculosis within macrophages. Infect. Immun. 59, 1755-1761.

Chang, Z., Choudhary, A., Lathigra, R., and Quiocho, F. A. (1994). The immunodominant 38-kDa lipoprotein antigen of Mycobacterium tuberculosis is a phosphate-binding protein. J. Biol. Chem. 269, 1956-1958.

Chanteau, S., Rasolofo, V., Rasolonavalona, T., Ramarokoto, H., Horn, C., Auregan, G., et al. (2000). 45/47 kilodalton (APA) antigen capture and antibody detection assays for the diagnosis of tuberculosis. Int. J. Tuberc. Lung Dis. 4, 377-383.

Choudhry, V., and Saxena, R. K. (2002). Detection of Mycobacterium tuberculosis antigens in urinary proteins of tuberculosis patients. Eur. J. Clin. Microbiol. Infect. Dis. 21, 1-5. doi: 10.1007/s10096-001-0651-7

Constantine, N. T., and Zink, H. (2005). HIV testing technologies after two decades of evolution. Indian J. Med. Res. 121, 519-538.

Daley, P., Michael, J. S., Hmar, P., Latha, A., Chordia, P., Mathai, D., et al. (2009). Blinded evaluation of commercial urinary lipoarabinomannan for active tuberculosis: a pilot study. Int. J. Tuberc. Lung Dis. 13, 989-995.

Dheda, K., Davids, V., Lenders, L., Roberts, T., Meldau, R., Ling, D., et al. (2010). Clinical utility of a commercial LAM-ELISA assay for TB diagnosis in HIVinfected patients using urine and sputum samples. PLoS ONE 5:e9848. doi 10.1371/journal.pone.0009848

Doherty, M., Wallis, R. S., and Zumla, A. (2009). Biomarkers for tuberculosis disease status and diagnosis. Curr. Opin. Pulm. Med. 15, 181-187. doi: 10.1097/MCP.0b013e328326f42c

Drumm, J. E., Mi, K., Bilder, P., Sun, M., Lim, J., Bielefeldt-Ohmann, H., et al. (2009). Mycobacterium tuberculosis universal stress protein Rv2623 regulates bacillary growth by ATP-Binding: requirement for establishing chronic persistent infection. PLoS Pathog. 5:e1000460. doi: 10.1371/journal.ppat.1000460

El-Masry, S., El-Kady, I., Zaghloul, M. H., and Al-Badrawey, M. K. (2008) Rapid and simple detection of a Mycobacterium circulating antigen in serum of pulmonary tuberculosis patients by using a monoclonal antibody and FastDot-ELISA. Clin. Biochem. 41, 145-151. doi: 10.1016/j.clinbiochem.2007. 11.008

Fabre, M., Gerome, P., Maslin, J., Herve, V., Vong, R., Carpentier, G., et al. (2007). [Assessment of the Patho-TB kit for diagnosis of tuberculosis]. Pathol. Biol. (Paris) 55, 482-485. doi: 10.1016/j.patbio.2007.08.007

Flores, L. L., Steingart, K. R., Dendukuri, N., Schiller, I., Minion, J., Pai, M., etal. (2011). Systematic review and meta-analysis of antigen detection tests for the diagnosis of tuberculosis. Clin. Vaccine Immunol. 18, 1616-1627. doi: 10.1128/CVI.05205-11
Haldar, S., Sankhyan, N., Sharma, N., Bansal, A., Jain, V., Gupta, V. K., et al. (2012). Detection of Mycobacterium tuberculosis GlcB or HspX Antigens or devR DNA impacts the rapid diagnosis of tuberculous meningitis in children. PLOS ONE 7:e44630. doi: 10.1371/journal.pone.0044630

Hamasur, B., Bruchfeld, J., Haile, M., Pawlowski, A., Bjorvatn, B., Källenius, G., et al. (2001). Rapid diagnosis of tuberculosis by detection of mycobacterial lipoarabinomannan in urine. J. Microbiol. Methods 45, 41-52. doi: 10.1016/S01677012(01)00239-1

Hillemann, D., Rusch-Gerdes, S., Boehme, C., and Richter, E. (2011). Rapid molecular detection of extrapulmonary tuberculosis by the automated GeneXpert MTB/RIF system. J. Clin. Microbiol. 49, 1202-1205. doi: 10.1128/JCM.02268-10

Hunter, S. W., Gaylord, H., and Brennan, P. J. (1986). Structure and antigenicity of the phosphorylated lipopolysaccharide antigens from the leprosy and tubercle bacilli. J. Biol. Chem. 261, 12345-12351.

Jain, A. (2011). Extra pulmonary tuberculosis: a diagnostic dilemma. Indian J. Clin. Biochem. 26, 269-273. doi: 10.1007/s12291-010-0104-0

Jain, R. K., Nayak, A. R., Husain, A. A., Panchbhai, M. S., Chandak, N., Purohit, H. J., et al. (2013). Mycobacterial dormancy regulon protein Rv2623 as a novel biomarker for the diagnosis of latent and active tuberculous meningitis. Dis. Markers 35, 311-316. doi: 10.1155/2013/309816

Kashino, S. S., Pollock, N., Napolitano, D. R., Rodrigues, V. Jr., and Campos-Neto, A. (2008). Identification and characterization of Mycobacterium tuberculosis antigens in urine of patients with active pulmonary tuberculosis: an innovative and alternative approach of antigen discovery of useful microbial molecules. Clin. Exp. Immunol. 153, 56-62. doi: 10.1111/j.1365-2249.2008. 03672.x

Kashyap, R. S., Rajan, A. N., Ramteke, S. S., Agrawal, V. S., Kelkar, S. S., Purohit, H. J., et al. (2007). Diagnosis of tuberculosis in an Indian population by an indirect ELISA protocol based on detection of Antigen 85 complex: a prospective cohort study. BMC Infect. Dis. 7:74. doi: 10.1186/1471-2334-7-74

Kashyap, R. S., Ramteke, S. S., Morey, S. H., Purohit, H. J., Taori, G. M., and Daginawala, H. F. (2009). Diagnostic value of early secreted antigenic target-6 for the diagnosis of tuberculous meningitis patients. Infection 37, 508-513. doi: 10.1007/s15010-009-8261-x

Lawn, S. D. (2014). Serological diagnostic assays for HIV-associated tuberculosis in Sub-Saharan Africa? Clin. Vaccine Immunol. 21, 787-790. doi: 10.1128/CVI.00201-14

Lawn, S. D., Dheda, K., Kerkhoff, A. D., Peter, J. G., Dorman, S., Boehme, C. C., et al. (2013). Determine TB-LAM lateral flow urine antigen assay for HIV-associated tuberculosis: recommendations on the design and reporting of clinical studies. BMC Infect. Dis. 13:407. doi: 10.1186/1471-2334-13-407

Lawn, S. D., Edwards, D. J., Kranzer, K., Vogt, M., Bekker, L. G., and Wood, R. (2009). Urine lipoarabinomannan assay for tuberculosis screening before antiretroviral therapy diagnostic yield and association with immune reconstitution disease. AIDS 23, 1875-1880. doi: 10.1097/QAD.0b013e32832e05c8

Lawn, S. D., Kerkhoff, A. D., Vogt, M., and Wood, R. (2012). Diagnostic accuracy of a low-cost, urine antigen, point-of-care screening assay for HIV-associated pulmonary tuberculosis before antiretroviral therapy: a descriptive study. Lancet Infect. Dis. 12, 201-209. doi: 10.1016/S1473-3099(11)70251-1

Lew, J. M., Kapopoulou, A., Jones, L. M., and Cole, S. T. (2011). TubercuList - 10 years after. Tuberculosis (Edinb.) 91, 1-7. doi: 10.1016/j.tube.2010.09.008

Malen, H., Berven, F. S., Fladmark, K. E., and Wiker, H. G. (2007). Comprehensive analysis of exported proteins from Mycobacterium tuberculosis H37Rv. Proteomics 7, 1702-1718. doi: 10.1002/pmic.200600853

Mattow, J., Schaible, U. E., Schmidt, F., Hagens, K., Siejak, F., Brestrich, G., et al. (2003). Comparative proteome analysis of culture supernatant proteins from virulent Mycobacterium tuberculosis $\mathrm{H} 37 \mathrm{Rv}$ and attenuated M. bovis BCG Copenhagen. Electrophoresis 24, 3405-3420. doi: 10.1002/elps.200305601

McNerney, R., Maeurer, M., Abubakar, I., Marais, B., McHugh, T. D., Ford, N., et al. (2012). Tuberculosis diagnostics and biomarkers: needs, challenges, recent advances, and opportunities. J. Infect. Dis. 205(Suppl. 2), S147-S158. doi: 10.1093/infdis/jir860

Minion, J., Leung, E., Talbot, E., Dheda, K., Pai, M., and Menzies, D. (2011). Diagnosing tuberculosis with urine lipoarabinomannan: systematic review and meta-analysis. Eur. Respir. J. 38, 1398-1405. doi: 10.1183/09031936. 00025711

Mutetwa, R., Boehme, C., Dimairo, M., Bandason, T., Munyati, S. S., Mangwanya, D., et al. (2009). Diagnostic accuracy of commercial urinary lipoarabinomannan 
detection in African tuberculosis suspects and patients. Int. J. Tuberc. Lung Dis. $13,1253-1259$.

Napolitano, D. R., Pollock, N., Kashino, S. S., Rodrigues, V. Jr., and Campos-Neto, A. (2008). Identification of Mycobacterium tuberculosis ornithine carboamyltransferase in urine as a possible molecular marker of active pulmonary tuberculosis. Clin. Vaccine Immunol. 15, 638-643. doi: 10.1128/CVI.00010-08

Pai, N. P., and Pai, M. (2012). Point-of-care diagnostics for HIV and tuberculosis: landscape, pipeline, and unmet needs. Discov. Med. 13, 35-45.

Pereira Arias-Bouda, L. M., Nguyen, L. N., Ho, L. M., Kuijper, S., Jansen, H. M., and Kolk, A. H. (2000). Development of antigen detection assay for diagnosis of tuberculosis using sputum samples. J. Clin. Microbiol. 38, 2278-2283.

Peter, J. G., Theron, G., van Zyl-Smit, R., Haripersad, A., Mottay, L., Kraus, S., et al. (2012). Diagnostic accuracy of a urine LAM strip-test for TB detection in HIV-infected hospitalised patients. Eur. Respir. J. 40, 1211-1220. doi: 10.1183/09031936.00201711

Pollock, N. R., Macovei, L., Kanunfre, K., Dhiman, R., Restrepo, B. I., Zarate, I., et al. (2013). Validation of Mycobacterium tuberculosis Rv1681 protein as a diagnostic marker of active pulmonary tuberculosis. J. Clin. Microbiol. 51, 1367-1373. doi: 10.1128/JCM.03192-12

Rajan, A. N., Kashyap, R. S., Purohit, H. J., Taori, G. M., and Daginawala, H. F. (2007). Serodiagnosis of tuberculosis based on the analysis of the $65 \mathrm{kD}$ heat shock protein of Mycobacterium tuberculosis. Int. J. Tuberc. Lung Dis. 11, 792-797.

Reddy, T. B. K., Riley, R., Wymore, F., Montgomery, P., DeCaprio, D., Engels, R., et al. (2009). TB database: an integrated platform for tuberculosis research. Nucleic Acids Res. 37(Suppl. 1), D499-D508. doi: 10.1093/nar/gkn652

Reither, K., Saathoff, E., Jung, J., Minja, L. T., Kroidl, I., Saad, E., et al. (2009). Low sensitivity of a urine LAM-ELISA in the diagnosis of pulmonary tuberculosis. BMC Infect. Dis. 9:141. doi: 10.1186/1471-2334-9-141

Reither, K., Saathoff, E., Jung, J., Minja, L. T., Machibya, H., Maboko, L., et al. (2010). Evaluation of Diagnos TB AG, a flow-through immunoassay for rapid detection of pulmonary tuberculosis. Int. J. Tuberc. Lung Dis. 14, 238-240.

Savolainen, L., Kantele, A., Sandboge, B., Siren, M., Valleala, H., Tuompo, R., et al. (2013). Modification of clearview tuberculosis (TB) enzyme-linked immunosorbent assay for TB patients not infected with HIV. Clin. Vaccine Immunol. 20 1479-1482. doi: 10.1128/CVI.00375-13

Shah, M., Martinson, N. A., Chaisson, R. E., Martin, D. J., Variava, E., and Dorman, S. E. (2010). Quantitative analysis of a urine-based assay for detection of lipoarabinomannan in patients with tuberculosis. J. Clin. Microbiol. 48, 2972-2974. doi: 10.1128/JCM.00363-10

Steingart, K. R., Flores, L. L., Dendukuri, N., Schiller, I., Laal, S., Ramsay, A., et al. (2011). Commercial serological tests for the diagnosis of active pulmonary and extrapulmonary tuberculosis: an updated systematic review and meta-analysis. PLoS Med. 8:e1001062. doi: 10.1371/journal.pmed.1001062

Steingart, K. R., Ramsay, A., Dowdy, D. W., and Pai, M. (2012). Serological tests for the diagnosis of active tuberculosis: relevance for India. Indian J. Med. Res. 135, 695-702.

Tiwari, R. P., Hattikudur, N. S., Bharmal, R. N., Kartikeyan, S., Deshmukh, N. M., and Bisen, P. S. (2007). Modern approaches to a rapid diagnosis of tuberculosis: promises and challenges ahead. Tuberculosis (Edinb.) 87, 193-201. doi: 10.1016/j.tube.2006.07.005
Wallis, R. S., Pai, M., Menzies, D., Doherty, T. M., Walzl, G., Perkins, M. D., et al. (2010a). Biomarkers and diagnostics for tuberculosis: progress, needs, and translation into practice. Lancet 375, 1920-1937. doi: 10.1016/S0140-6736(10) 60359-5

Wallis, R. S., Wang, C., Doherty, T. M., Onyebujoh, P., Vahedi, M., Laang, H., et al. (2010b). Biomarkers for tuberculosis disease activity, cure, and relapse. Lancet Infect. Dis. 10, 68-69. doi: 10.1016/S1473-3099(10) 70003-7

Wallis, R. S., Perkins, M., Phillips, M., Joloba, M., Demchuk, B., Namale, A., etal. (1998). Induction of the antigen 85 complex of Mycobacterium tuberculosis in sputum: a determinant of outcome in pulmonary tuberculosis treatment. J. Infect. Dis. 178, 1115-1121. doi: 10.1086/ 515701

World Health Organization (WHO). (2009). Pathways to Better Diagnostics for Tuberculosis: A Blueprint for the Development of TB Diagnostics by the New Diagnostics Working Group of the Stop TB Partnership. Geneva: World Health Organization.

World Health Organization (WHO). (2011a). Policy Statement: Automated Realtime Nucleic Acid Amplification Technology for Rapid and Simultaneous Detection of Tuberculosis and Rifampicin Resistance: Xpert MTB/RIF System. Geneva: World Health Organization.

World Health Organization (WHO). (2011b). Commercial Serodiagnostic Tests for Diagnosis of Tuberculosis. Policy Statement. Geneva: World Health Organization.

World Health Organization (WHO). (2013). Global Tuberculosis Report 2013. Geneva: World Health Organization.

Xie, H., Mire, J., Kong, Y., Chang, M., Hassounah, H. A., Thornton, C. N., et al. (2012). Rapid point-of-care detection of the tuberculosis pathogen using a BlaC-specific fluorogenic probe. Nat. Chem. 4, 802-809. doi: 10.1038/ nchem. 1435

Young, D. B., Perkins, M. D., Duncan, K., and Barry, C. E. III. (2008). Confronting the scientific obstacles to global control of tuberculosis. J. Clin. Invest. 118, 12551265. doi: $10.1172 / \mathrm{JCI} 34614$

Conflict of Interest Statement: The authors declare that the research was conducted in the absence of any commercial or financial relationships that could be construed as a potential conflict of interest.

Received: 19 August 2014; paper pending published: 22 September 2014; accepted: 01 October 2014; published online: 20 October 2014.

Citation: Tucci P, González-Sapienza G and Marin M (2014) Pathogen-derived biomarkers for active tuberculosis diagnosis. Front. Microbiol. 5:549. doi: 10.3389/ fmicb.2014.00549

This article was submitted to Infectious Diseases, a section of the journal Frontiers in Microbiology.

Copyright (c) 2014 Tucci, González-Sapienza and Marin. This is an open-access article distributed under the terms of the Creative Commons Attribution License (CC BY). The use, distribution or reproduction in other forums is permitted, provided the original author(s) or licensor are credited and that the original publication in this journal is cited, in accordance with accepted academic practice. No use, distribution or reproduction is permitted which does not comply with these terms. 